Research

\title{
Performance of the EQ-5D and the EQ-5D+C in elderly patients with cognitive impairments
} Claire AG Wolfs ${ }^{1}$, Carmen D Dirksen*1, Alfons Kessels ${ }^{1}$,
Daniëlle CM Willems ${ }^{1}$, Frans RJ Verhey ${ }^{2}$ and Johan L Severens ${ }^{1,3}$

Address: ${ }^{1}$ Department of Clinical Epidemiology and Medical Technology Assessment, Maastricht University Hospital, Maastricht, Netherlands, ${ }^{2}$ Department of Psychiatry \& Neuropsychology, Maastricht University, Maastricht, Netherlands and ${ }^{3}$ Department of Health Organisation, Policy and Economics, Maastricht University, Netherlands

Email: Claire AG Wolfs - claire.wolfs@np.unimaas.nl; Carmen D Dirksen* - cdir@kemta.azm.nl; Alfons Kessels - akes@kemta.azm.nl; Daniëlle CM Willems - dwill@kemta.azm.nl; Frans RJ Verhey - f.verhey@np.unimaas.nl; Johan L Severens - h.severens@beoz.unimaas.nl

* Corresponding author

Published: 14 June 2007

Health and Quality of Life Outcomes 2007, 5:33 doi:10.1 I86/1477-7525-5-33

This article is available from: http://www.hqlo.com/content/5/I/33

(C) 2007 Wolfs et al; licensee BioMed Central Ltd.

This is an Open Access article distributed under the terms of the Creative Commons Attribution License (http://creativecommons.org/licenses/by/2.0), which permits unrestricted use, distribution, and reproduction in any medium, provided the original work is properly cited.

\begin{abstract}
Background: The EQ-5D is a reliable tool for measuring Health-Related Quality of Life (HRQoL). However, concern has been expressed that it may ignore elements of HRQoL, particularly cognition. In response to this concern, the EQ-5D has been extended with a cognitive dimension $(E Q-5 D+C)$. The aim of this study was to compare the performance of the EQ-5D and the EQ$5 D+C$ in elderly patients with cognitive impairments by assessing their construct validity and responsiveness.
\end{abstract}

Methods: Data from the MEDICIE study $(n=196)$ were used, in which all questionnaires were rated by proxies.

Results: Regarding construct validity, we found similar correlations between the EQ-5D and the Mini Mental State Examination (MMSE) and between the EQ-5D+C and the MMSE. Furthermore, both the EQ-5D and the EQ-5D+C were responsive to changes in the MMSE, with the EQ-5D performing slightly better.

Conclusion: We conclude that the EQ-5D performs well for evaluating HRQoL in a population with cognitive impairments. Based on the results of this explorative study, it does not seem necessary to adjust the current classification system by adding a cognitive dimension. However, in order to compare both instruments regarding utility values, it is necessary to develop a new scoring algorithm for the EQ-5D+C by conducting a general population study. Considering the explorative nature of this study, it is recommended that more aspects of the validity of both the EQ-5D and the EQ-5D+C are explored in patients with cognitive impairments using a more tailored study design.

\section{Background}

The increasing number of older adults who are diagnosed with dementia has far-reaching implications for health service delivery and expenditures [1]. Economic evaluations are performed more often to assist decision-makers in setting priorities, especially with regard to resource allo- 
cation [2]. A central component of economic evaluations in health care is the use of preference-based instruments (also called value-based instruments) to measure changes in Health-Related Quality of Life (HRQoL). Preferencebased measures, such as the EQ-5D [3,4], the SF-6D [5] and the HUI [6], are standardized multi-dimensional health state classifications [7]. For each of these instruments, health states have been valued using techniques such as standard gamble (SG) or time trade-off (TTO) [8]. These valuations were used for each instrument to generate a scoring algorithm of which a single utility score for each health state can be deduced.

The EQ-5D is commonly used to measure HRQoL and has been shown to be responsive, internally consistent and reliable in the normal population and other patient groups $[9,10]$ as well as in patients with dementia [11,12]. However, concern has been raised that it may ignore elements of HRQoL of specific relevance to the elderly such as vision and hearing [1] and in particular cognition $[1,13-17]$. It is known that cognitive problems have an impact on personality, mood, behavior and global functioning [18], which are domains covered by the EQ-5D, but cognition might also be regarded as a separate dimension.

In response to the concern that the $\mathrm{EQ}-5 \mathrm{D}$ ignores cognition, the EQ-5D has been extended with a cognitive dimension (EQ-5D+C)[15]. In this study of Krabbe et al. (which was an adapted Dutch replication of the Global Burden of Disease study commissioned by the World Bank) [19], valuations (by means of a rating scale) elicited from EQ-5D+C descriptions were compared empirically with parallel EQ-5D descriptions in Dutch faculty members (i.e. scientific staff members and management members of the Department of Public Health, the Department of Clinical Epidemiology and Biostatics and the Institute of Social Medicine).

The EQ-5D+C generated different values compared with the EQ-5D. Whereas the content validity of the EQ-5D improved by adding cognition, both versions evoked equally reliable values. Based on these results, the authors emphasized the importance of considering the inclusion of a cognitive dimension. Furthermore, the EQ-5D+C was used to describe the health status of the Dutch population and to investigate sociodemographic differences [14].

In this study, the content validity also improved through the addition of the cognitive dimension, while the reliability remained unaltered. It was concluded by the authors that the EQ-5D+C is an efficient tool for establishing the health status in the community. Another way to examine if the EQ-5D should contain a cognitive dimension is to investigate the performance of the EQ-5D and the $\mathrm{EQ}-5 \mathrm{D}+\mathrm{C}$ in a population with cognitive impairments. The aim of this explorative study was to compare the performance of the EQ-5D and the $\mathrm{EQ}-5 \mathrm{D}+\mathrm{C}$ by assessing their construct validity and responsiveness in patients aged 55 and older with cognitive impairments.

\section{Methods \\ Study population and data collection}

Data were derived from the MEDICIE (Maastricht Evaluation of a Diagnostic Intervention for Cognitively Impaired Elderly) study. The MEDICIE study is a randomized controlled trial (RCT) comparing the effects of a multidisciplinary diagnostic observation center for psychogeriatric patients (DOC-PG) with care as usual on HRQoL, mental and physical health, and the costs and use of health care facilities by patients with psychogeriatric problems [20]. The DOC-PG is an outpatient facility, providing multidisciplinary assessment by somatic screening, psychogeriatric assessment, and evaluation of the required levels of care for the patient and his (her) carer. The main aim of the DOC-PG is to improve or maintain the HRQoL of patients.

In the MEDICIE study, a total of 234 patients and their caregivers agreed to participate and were included between July 2002 and October 2004. Randomization occurred at the level of general practices. The experimental group visited the new diagnostic facility (DOC-PG), whereas the control group was treated as usual, i.e. the GP made the diagnosis or referred the patient to a specialist facility, namely the Maastricht Memory Clinic (MMC) or the Department of Old Age Psychiatry of the Community Mental Health Service (RIAGG). Patients were followed up after 6 months and 12 months.

All outcome measures, except the Mini Mental State Examination (MMSE), were collected through personal interviews with the patient's proxy. After initial assessment by the aforementioned health care professionals, the baseline MMSE scores were gathered from the patient records. The researchers (C.W. and D.W) were trained to assess patients using the MMSE at the 6 and 12 month follow-up. When possible, follow-up scores by the professionals were used. Sociodemographic data of the patients (gender, age, living arrangements) and proxies (gender, age, relationship to patient) were collected at baseline. Diagnosis was established by the multidisciplinary teams working at the DOC-PG or the MMC/RIAGG respectively, and was based on the DSM-IV criteria or other regular criteria [21]. In this study, the baseline data and the data at the six and 12 month follow-up for the entire group were used since, for the purpose of this paper, it was not necessary to analyze the data of the control group and the experimental group separately. 


\section{Instruments}

Mini Mental State Examination (MMSE)

The MMSE is used to detect cognitive impairment, to assess its severity and to monitor cognitive changes over time [22]. The MMSE has a maximum score of 30 points, with different domains being assessed: orientation in regard to time and place (10 points), registration of three words (3 points), attention and calculation (5 points), recall of three words ( 3 points), language ( 8 points), and visual construction ( 1 point). Scores below 24 are considered abnormal and this is the cut-off used for dementia. Scores in the MMSE are often classified into different categories: 26-30 (normal ageing), 21-25 (mild dementia), 15-20 (moderate dementia), 10-14 (moderately severe dementia) and 0-9 (severe dementia). The MMSE has demonstrated validity and reliability in geriatric, psychiatric, neurological and other medical populations [23], also in the Netherlands [24].

\section{$E Q-5 D$ and $E Q-5 D+C$}

The EQ-5D is a generic instrument to measure HRQoL. The instrument was developed and validated in a number of European countries including the Netherlands $[3,25,26]$. The EQ-5D describes health status according to five dimensions: mobility, self-care, usual activities, pain/ discomfort and anxiety/depression. Each dimension has three levels, namely, "no problems", "some problems" and "severe problems". This yields 243 potential combinations of health states across the five dimensions. Dolan et al. [27] have presented 42 of these health states to members of a representative sample of the UK general population, which were valued using the TTO method. Based on these valuations, utility scores can be deduced by means of an additive function. These are now widely used in costutility analyses [28]. Utility scores can vary between -0.59 (worst health) and 1.00 (perfect health). Besides the five dimensions, the EQ-5D consists of a visual analogue scale $\left(\mathrm{VAS}_{5 \mathrm{D}}\right)$ ranging from 0 (worst imaginable health state) to 100 (best imaginable health state).

The EQ-5D+C is an extended version of the EQ-5D that includes "cognitive functioning" (memory, concentration, coherence, IQ) as an additional dimension, with a similar operationalization of three levels (as described above) [15]. The EQ-5D+C also includes a $\mathrm{VAS}_{5 \mathrm{D}}$.

In this study, the EQ-5D was administered completely first, that is the five dimensions followed by the $\mathrm{VAS}_{5 \mathrm{D}}$. Subsequently, the proxies were asked to answer the sixth dimension concerning cognitive functioning, whereupon the $\mathrm{VAS}_{5 \mathrm{D}}$ was valued a second time (in this study referred to as the $\left.\mathrm{VAS}_{5 \mathrm{D}+\mathrm{C}}\right)$. Therefore, in this study, the EQ-5D+C refers to the additional cognitive functioning dimension and the $\mathrm{VAS}_{5 \mathrm{D}+\mathrm{C}}$.

\section{Data analysis \\ Construct validity}

Construct validity, the extent to which an instrument correlates with other measures which it should be related to [29], was estimated by studying correlations between the EQ-5D and the MMSE and between the EQ-5D+C and the MMSE at baseline and follow-up measures. Although it was expected that effects of cognitive impairment were implicitly expressed in the EQ-5D dimensions concerning self-care, usual activities and anxiety/depression [18,30], we hypothesized that the correlations between the EQ$5 \mathrm{D}+\mathrm{C}$ and the MMSE were strongest.

\section{Responsiveness}

In this study, responsiveness was defined as the correlation of the changes in an instrument to changes in other measures which it should be related to, using an anchorbased approach $[31,32]$. We evaluated whether changes in the EQ-5D and changes in the EQ-5D+C correlated with changes in the MMSE, the so-called anchor (external standard). Again, it was hypothesized that the correlations between the $\mathrm{EQ}-5 \mathrm{D}+\mathrm{C}$ and the MMSE were stronger than the correlations between the EQ-5D and the MMSE.

\section{Statistical analysis}

The software used for the analyses was SPSS version 12.0.1 and STATA version 8.2. Background characteristics of the participants (both the patients and their proxies) were summarized using descriptive statistics. Response distributions of the instruments (EQ-5D, EQ-5D+C and MMSE) are given. Missing data of the participants were imputed using multiple imputation (MI). MI provides a useful strategy for dealing with data sets with missing values. Instead of filling in a single value for each missing value, Rubin's [33] multiple imputation procedure replaces each missing value with a set of plausible values (5) that represent the uncertainty about the right value to impute. This results in statistically valid inferences that properly reflect the uncertainty due to missing values.

Kolmogorov-Smirnov tests were used to test for normality. Non-parametric tests for comparisons were selected. Associations between the instruments were analyzed with Spearman rank correlations.

\section{Results}

\section{Sample characteristics}

Table 1 summarizes sample characteristics. Of the 234 patients that were included in the MEDICIE-study, $64.1 \%$ were females. Of the proxies, $66.7 \%$ were females and mostly children (-in-law) or spouses of the patient (90.2\%). In most cases, dementia (present in $70.1 \%$ of the patients) was associated with Alzheimer's disease (41.5\%). Patients whose etiological diagnoses could not 
be determined were assigned to the "other" groups (i.e. other dementia or other cognitive impairment).

After six months, 16 patients $(6.8 \%)$ had died and 11 patients $(4.7 \%)$ and their caregivers had dropped out of the study. Four patients $(1.7 \%)$ did not attend the six month follow-up because of personal reasons. After 12 months another 11 patients $(4.7 \%)$ had died and two more patients $(0.9 \%)$ and their caregivers had dropped out of the study. The 27 patients $(11.5 \%)$ who had died were excluded from the analyses as well as the 11 study dropouts $(4.7 \%)$ who completed only 1 measurement. Missing data of the remaining 196 patients were imputed using MI. To make sure the imputations did not influence our results, separate analyses were performed on the 5 imputed datasets. The results were highly comparable (data not shown). Therefore, the first imputed dataset was used for analysis.

\section{Responses in the EQ-5D, EQ-5D+C and MMSE}

The responses in the EQ-5D and the $\mathrm{EQ}-5 \mathrm{D}+\mathrm{C}$ at baseline and follow-up measurements are summarized in table 2. At baseline as well as at the 6 month follow-up, most patients had problems with cognitive functioning, usual activities and mobility. At the 12 month follow-up, most patients had problems with cognitive functioning, usual activities and self-care. The mean $\mathrm{VAS}_{5 \mathrm{D}+\mathrm{C}}$ scores were significantly lower than the mean $\mathrm{VAS}_{5 \mathrm{D}}$ scores at all measurements (Wilcoxon Signed Ranks Tests, $\mathrm{p}=0.000$ ).

The responses in the MMSE at baseline and follow-up measurements are summarized in table 3. Most patients had mild to moderate dementia at all measurements.

\section{Construct validity}

Table 4 summarizes the results of the correlations between the MMSE and the EQ-5D and between the MMSE and the EQ-5D+C. At baseline, significant correlations were found between the MMSE and the utility score, and more specifically the self-care dimension and the usual activities dimension, and the VAS ${ }_{5 \mathrm{D}}$ of the EQ-5D. Correlations were also found between the MMSE and the cognitive dimension and the $\mathrm{VAS}_{5 \mathrm{D}+\mathrm{C}}$ of the EQ-5D+C. At the six month follow-up, correlations were found between the MMSE and the utility score, and more specifically all five dimensions, and the $\mathrm{VAS}_{5 \mathrm{D}}$ of the EQ-5D. Correlations were also found between the MMSE and the cognitive dimension and the $\mathrm{VAS}_{5 \mathrm{D}+\mathrm{C}}$ of the $\mathrm{EQ}-5 \mathrm{D}+\mathrm{C}$. At the 12 month follow-up, correlations were found between the MMSE and the utility score, and more specifically all dimensions except for the pain/discomfort dimension, and the VAS 5 D of the EQ-5D. Correlations were also found between the MMSE and the cognitive dimension and the $\mathrm{VAS}_{5 \mathrm{D}+\mathrm{C}}$ of the EQ-5D+C.

\section{Responsiveness}

Table 5 summarizes the results of the correlations between the change scores of the EQ-5D and the EQ$5 \mathrm{D}+\mathrm{C}$ and the change scores of the MMSE. In table 6 , the means for the change scores are outlined. Regarding the difference between the six month measurement and the baseline measurement, correlations were found between changes in the utility score, more specifically the self-care dimension, of the EQ-5D and the change scores of the MMSE. Correlations were also found between changes in the cognitive dimension of the $\mathrm{EQ}-5 \mathrm{D}+\mathrm{C}$ and change scores of the MMSE. Regarding the difference between the 12 month measurement and the baseline measurement, correlations were found between changes in the utility score, more specifically the mobility dimension, the selfcare dimension and the usual activities dimension, and the $\mathrm{VAS}_{5 \mathrm{D}}$ of the EQ-5D and the change scores of the MMSE. Correlations were also found between changes in the cognitive dimension and the $\mathrm{VAS}_{5 \mathrm{D}+\mathrm{C}}$ of the EQ-5D+C and the change scores of the MMSE.

\section{Discussion}

The aim of this explorative study was to compare the performance of the EQ-5D and the EQ-5D+C by assessing their construct validity and responsiveness in patients aged 55 and older with cognitive impairments.

Based on our results it can be concluded that the construct validity of the EQ-5D and the $\mathrm{EQ}-5 \mathrm{D}+\mathrm{C}$ is comparable in our study population, except for the $\mathrm{VAS}_{5 \mathrm{D}}$. Results regarding construct validity of the EQ-5D are in line with the recent findings of Jönssen et al. [17]. Contrary to our expectations, correlations between the cognitive dimension and the MMSE were almost similar to the correlations between the self-care and the usual activities dimensions and the MMSE. The presence of more and stronger correlations of both the EQ-5D and EQ-5D+C with the MMSE at the 12 month follow up measurement was possibly due to the fact that the dispersion of the scores using these instruments increased with time. Three studies also showed that cognitive function was positively related to HRQoL in cardiac rehabilitation patients [34], in patients with progressive supranuclear palsy [35] and in patients with hypertension [36]. Another study [37] failed to find a relationship between HRQoL and cognition in patients with dementia.

With regard to responsiveness, the EQ-5D performed slightly better than the EQ- $5 \mathrm{D}+\mathrm{C}$, which is also in line with the findings of Jönssen [17]. An important finding, again contrary to our expectations, is that changes in the MMSE corresponded better with changes in the self-care dimension and the usual activities dimension than with changes in the cognitive dimension. 
Table I: Sample characteristics at baseline

\begin{tabular}{|c|c|}
\hline & Total $n=234$ \\
\hline \multicolumn{2}{|l|}{ Gender of patient: } \\
\hline Female (\%) & 150 (64.1\%) \\
\hline \multicolumn{2}{|l|}{ Age of patient: } \\
\hline Mean (SD) & $77.8(6.7)$ \\
\hline Range & [55-94] \\
\hline \multicolumn{2}{|l|}{ Relationship proxy: } \\
\hline Spouse & $88(37.6 \%)$ \\
\hline Child (-in-law) & $123(52.6 \%)$ \\
\hline Other & $23(9.8 \%)$ \\
\hline \multicolumn{2}{|l|}{ Gender of proxy: } \\
\hline Female (\%) & $156(66.7 \%)$ \\
\hline \multicolumn{2}{|l|}{ Age of proxy: } \\
\hline Mean (SD) & $59.8(13.9)$ \\
\hline Range & [30-91] \\
\hline \multicolumn{2}{|l|}{ MMSE: } \\
\hline Mean (SD) & $20.18(5.8)$ \\
\hline Dementia: & 164 (70.1\%) \\
\hline Alzheimer's Disease (AD) & $97(41.5 \%)$ \\
\hline Vascular Dementia (VD) & $26(11.1 \%)$ \\
\hline Mixed Dementia & $21(9.0 \%)$ \\
\hline Other Dementia & $20(8.5 \%)$ \\
\hline No Dementia: & 70 (29.9\%) \\
\hline Cognitive Impairment/MCI & $40(17.1 \%)$ \\
\hline Other Cognitive Impairment & $30(12.8 \%)$ \\
\hline
\end{tabular}

However, no judgments were made about the strength of the correlations, which would provide us with a stricter criterion regarding the performance of the EQ-5D and $\mathrm{EQ}-5 \mathrm{D}+\mathrm{C}$. In the literature, different classifications were found [38-41] a clear gold standard being absent. We therefore ignored the classifications and merely described our results. However, it is possible to compare our results with other studies. Our results were in line with correlations between the EQ-5D and clinical measures found in other studies involving diseases such as progressive supranuclear palsy (PSP) [35], rheumatoid arthritis (RA) [39] and stroke [42].

The majority of authors $[39,41,42]$ and others) considered a Spearman's correlation of $>0.50$ to be strong, a correlation of $0.30 / 0.35-0.50$ to be moderate and a correlation $<0.30 / 0.35$ to be weak. Using these classifications in our study, it can be concluded that both versions performed well with respect to construct validity, as indicated by strong correlations with the MMSE. Regarding responsiveness, it can be concluded that the EQ-5D performed moderately, whereas the $\mathrm{EQ}-5 \mathrm{D}+\mathrm{C}$ did less well as indicated by weak correlations with the MMSE. When the more stringent classification of Landis and Koch [38] is used (i.e. $<0.00$ poor; $0.00-0.20$ slight; $0.21-0.40$ fair; 0.41-0.60 moderate; $0.61-0.80$ substantial and 0.811.00 almost perfect), it can be concluded that the EQ-5D and the EQ-5D+C performed moderately with regard to the construct validity.
Regarding responsiveness, fair correlations were found between changes in the EQ-5D and EQ-5D+C and changes in the MMSE. The relatively low responsiveness of the EQ-5D in this study could be due to the, on average, small changes in cognition in a year, or to a ceiling effect because there are only three levels for each dimension of the EQ-5D. Patients' health may improve or decline but not enough to go up or down one level. Instruments that have a greater number of possible responses may be more responsive. Furthermore, it is possible that adaptation to illness on the part of the proxy leads to a lack of responsiveness, especially with a chronic condition such as dementia [39]. It should also be noted that a lack of clarity exists with regard to the definition and adequate approach for evaluating responsiveness. Some authors argued that there is no need for an additional concept like responsiveness, since it can be viewed as either longitudinal validity or magnitude of the treatment effect $[32,43,44]$. The definition and approach used in this study has also been referred to as longitudinal validity [32].

There are several limitations to this study that need to be recognized. An important limitation of this study concerns our study design. The origin of this study, the MEDICIE trial, was designed to compare the effects of a multidisciplinary diagnostic observation centre for psychogeriatric patients (DOC-PG) with care as usual on HRQoL, mental and physical health, and the costs and use of health care facilities by patients with psychogeriatric 
Table 2: Responses in the EQ-5D and EQ-5D+C (items, utility scores and VAS scores)

\begin{tabular}{|c|c|c|c|}
\hline$E Q-5 D N=196$ & Baseline & 6 months & 12 months \\
\hline \multicolumn{4}{|l|}{ Mobility: } \\
\hline Mean (SD) & $1.65(0.48)$ & $\mathrm{I} .65(0.5 \mathrm{I})$ & $\mathrm{I} .67(0.5 \mathrm{I})$ \\
\hline$\%$ no problems & $24.7 \%$ & $36.7 \%$ & $34.7 \%$ \\
\hline$\%$ some problems & $65.3 \%$ & $61.7 \%$ & $63.3 \%$ \\
\hline$\%$ severe problems & $0 \%$ & $1.5 \%$ & $2.0 \%$ \\
\hline \multicolumn{4}{|l|}{ Self-Care: } \\
\hline Mean (SD) & $1.59(0.65)$ & $1.71(0.73)$ & $1.97(0.80)$ \\
\hline \% no problems & $50.0 \%$ & $45.4 \%$ & $33.2 \%$ \\
\hline$\%$ some problems & $40.8 \%$ & $38.3 \%$ & $36.7 \%$ \\
\hline$\%$ severe problems & $9.2 \%$ & $16.3 \%$ & $30.1 \%$ \\
\hline \multicolumn{4}{|l|}{ Usual Activities: } \\
\hline Mean (SD) & $1.92(0.72)$ & $2.02(0.75)$ & $2.17(0.78)$ \\
\hline$\%$ no problems & $29.6 \%$ & $27.0 \%$ & $23.0 \%$ \\
\hline \% some problems & $48.5 \%$ & $44.4 \%$ & $36.7 \%$ \\
\hline$\%$ severe problems & $21.9 \%$ & $28.6 \%$ & $40.3 \%$ \\
\hline \multicolumn{4}{|l|}{ Pain/Discomfort: } \\
\hline Mean (SD) & $1.59(0.65)$ & $1.51(0.60)$ & $1.54(0.62)$ \\
\hline$\%$ no problems & $49.5 \%$ & $54.1 \%$ & $53.1 \%$ \\
\hline$\%$ some problems & $41.8 \%$ & $40.8 \%$ & $40.3 \%$ \\
\hline$\%$ severe problems & $8.7 \%$ & $5.1 \%$ & $6.6 \%$ \\
\hline \multicolumn{4}{|c|}{ Anxiety/Depression: } \\
\hline Mean (SD) & $1.66(0.67)$ & $1.53(0.59)$ & $1.54(0.68)$ \\
\hline$\%$ no problems & $44.9 \%$ & $52.6 \%$ & $56.6 \%$ \\
\hline$\%$ some problems & $43.9 \%$ & $42.3 \%$ & $33.2 \%$ \\
\hline$\%$ severe problems & $11.2 \%$ & $5.1 \%$ & $10.2 \%$ \\
\hline \multicolumn{4}{|l|}{ Utility score: } \\
\hline Mean (SD) & $0.54(0.31)$ & $0.57(0.32)$ & $0.47(0.34)$ \\
\hline Range & $-0.35-1.00$ & $-0.35-1.00$ & $-0.43-1.00$ \\
\hline \multicolumn{4}{|l|}{ VAS $_{5 \mathrm{D}}:$} \\
\hline Mean (SD) & $58.84(19.00)$ & $57.78(17.67)$ & $56.38(20.29)$ \\
\hline Range & $10-100$ & $20-100$ & $10-100$ \\
\hline \multicolumn{4}{|l|}{$E Q-5 D+C$} \\
\hline \multicolumn{4}{|l|}{ Cognition: } \\
\hline Mean (SD) & $2.30(0.58)$ & $2.35(0.64)$ & $2.47(0.61)$ \\
\hline$\%$ no problems & $6.1 \%$ & $8.7 \%$ & $6.1 \%$ \\
\hline$\%$ some problems & $58.2 \%$ & $47.4 \%$ & $40.8 \%$ \\
\hline$\%$ severe problems & $35.7 \%$ & $43.9 \%$ & $53.1 \%$ \\
\hline \multicolumn{4}{|l|}{$\operatorname{VAS}_{5 \mathrm{D}+\mathrm{c}}:$} \\
\hline Mean (SD) & $49.45(19.23)$ & $48.43(18.06)$ & $45.4 \mid(18.90)$ \\
\hline Range & $0-100$ & $10-90$ & $0-95$ \\
\hline
\end{tabular}

problems. Therefore, studying the usefulness of the EQ$5 \mathrm{D}+\mathrm{C}$ in this patient population was framed in this RCT. The EQ-5D was administered first, that is the five dimensions followed by the $\mathrm{VAS}_{5 \mathrm{D}}$. Subsequently, the proxies were asked to answer the sixth dimension concerning cognitive functioning, whereupon the $\mathrm{VAS}_{5 \mathrm{D}+\mathrm{C}}$ was valued. It would have been better to administer the EQ-5D+C completely as well in order to make valid comparisons between the 2 versions. However, considering the explorative nature of this study, we did not want to burden the participants of the MEDICIE trial by administering a similar questionnaire twice.

Second, regarding the assessment of the EQ-5D+C, the proxies may have focused their attention on the cognitive dimension when scoring the $\mathrm{VAS}_{5 \mathrm{D}+\mathrm{C}}$ even though they had been instructed to rate the $\mathrm{VAS}_{5 \mathrm{D}+\mathrm{C}}$ again based on the overall health. This effect is called a framing effect, which suggests that how something is presented (the 'frame') influences the choices people make [45]. Hence, it is pos- 
Table 3: Responses in the MMSE

\begin{tabular}{lccc}
\hline $\mathbf{N}=196$ & Baseline & $\mathbf{6}$ months & $\mathbf{1 2}$ months \\
\hline MMSE & & & $18.89(7.34)$ \\
Mean (SD) & $20.21(5.78)$ & & $17.61(8.16)$ \\
Severity of dementia: & $18.4 \%$ & $21.9 \%$ & $21.9 \%$ \\
$26-30$ (normal ageing) & $35.7 \%$ & $26.0 \%$ & $19.4 \%$ \\
$21-25$ (mild) & $29.6 \%$ & $25.0 \%$ & $25.0 \%$ \\
$15-20$ (moderate) & $10.2 \%$ & $14.3 \%$ & $15.3 \%$ \\
$10-14$ (moderately severe) & $6.1 \%$ & $12.8 \%$ & $18.4 \%$ \\
$0-9$ (severe) & & & \\
\hline
\end{tabular}

sible that the higher correlations of the $\mathrm{VAS}_{5 \mathrm{D}+\mathrm{C}}$ with the MMSE are due to a framing effect. However, according to Parkin et al. [46], the framing bias also exists when assessing the EQ-5D, meaning that values of the $\mathrm{VAS}_{5 \mathrm{D}}$ are affected by end-state descriptors (last named dimensions).

Another possible limitation is the use of proxies to complete the questionnaires. Previous research indicated that there is generally fairly good proxy-patient agreement for observable items such as mobility, self care and usual activities, but poor agreement for non-observable items such as pain and affect [16]. Others have found agreement to be poor for the domains most affected by dementia (self-care and usual activities) [17]. In the light of the longitudinal nature of our study, the complex health problems of our study population and their progressive global deterioration of intellect and personality, the method of proxy rating had been chosen. It is generally acknowledged that in the later stages of dementia proxy measures are required since patients are no longer capable of making an adequate evaluation of their HRQoL $[12,17]$. Furthermore, the use of proxy reports throughout the course of a longitudinal study, rather than substituting them only when the person with dementia becomes unable to report his or her HRQoL, reduces bias over time [47]. The overall picture of previous research is that rating by proxy is a valid alternative for assessing HRQoL in the presence of dementia [17,47-49], although it is possible that the scores in the EQ-5D and the EQ-5D+C were biased because of perceived caregiver burden [50].

A final limitation also concerns the design of our study. Comparisons between the EQ-5D and the EQ-5D+C were merely based on the dimensions and VAS-scores of both versions and not on the utility scores since these are not available for the EQ-5D+C. It should be noted that an algorithm has been developed for EQ-5D+C health states, based on Dutch disability weights $[51,52]$. In the Dutch disability weights study, a comprehensive set of diseasespecific disability weights for 175 disease stages associated with 52 disease categories was obtained $[53,54]$. Based on these disability weights, an $\mathrm{EQ}-5 \mathrm{D}+\mathrm{C}$ regression model was fitted. However, the origins of the EQ-5D+C disability weights and the EQ-5D utility scores differ significantly. First, the algorithm is based on valuations of health

Table 4: Spearman correlations between the EQ-5D and the MMSE and between the EQ-5D+C and the MMSE at baseline, six months and 12 months (construct validity)

\begin{tabular}{|c|c|c|c|}
\hline$N=196$ & Baseline & 6 months & 12 months \\
\hline \multicolumn{4}{|l|}{ EQ-5D: } \\
\hline Utility score & $0.19 * *$ & $0.45 * *$ & $0.50 * *$ \\
\hline Mobility & -0.02 & $-0.17^{*}$ & $-0.23^{* *}$ \\
\hline Self-Care & $-0.28 * *$ & $-0.50 * *$ & $-0.55^{* *}$ \\
\hline Usual activities & $-0.34 * *$ & $-0.42 * *$ & $-0.52^{* *}$ \\
\hline Pain/Discomfort & -0.01 & $-0.14^{*}$ & -0.05 \\
\hline Anxiety/Depression & -0.05 & $-0.17 *$ & $-0.22^{* *}$ \\
\hline $\mathrm{VAS}_{5 \mathrm{D}}$ & $0.22 * *$ & $0.23 * *$ & $0.23 * *$ \\
\hline \multicolumn{4}{|l|}{ EQ-5D+C: } \\
\hline Cognition & $-0.35 * *$ & $-0.52 * *$ & $-0.54 * *$ \\
\hline $\mathrm{VAS}_{5 \mathrm{D}+\mathrm{C}}$ & $0.37^{* *}$ & $0.47^{* * *}$ & $0.48 * *$ \\
\hline
\end{tabular}

** Correlation is significant at the 0.01 level (2-tailed)

* Correlation is significant at the 0.05 level (2-tailed) 
Table 5: Spearman correlations between the change scores of the EQ-5D and the MMSE, and between the EQ-5D+C and the MMSE, i.e. change score of baseline and six months and baseline and 12 months (longitudinal)

\begin{tabular}{lcc}
\hline Change scores $\mathbf{N}=196$ & Baseline \& 6 months & Baseline \& I2 months \\
EQ-5D: & & $0.30^{* *}$ \\
\hline Utility score & $0.16^{*}$ & $-0.17^{*}$ \\
Mobility & -0.11 & $-0.35^{* *}$ \\
Self-Care & $-0.18^{*}$ & $-0.29^{* *}$ \\
Usual activities & -0.12 & 0.03 \\
Pain/Discomfort & -0.04 & -0.12 \\
Anxiety/Depression & 0.00 & $0.17^{*}$ \\
VAS & & \\
EQ-5D+C: & 0.01 & \\
Cognition & & $-0.28^{* *}$ \\
VAS & &
\end{tabular}

** Correlation is significant at the 0.01 level (2-tailed)

* Correlation is significant at the 0.05 level (2-tailed)

experts instead of valuations of the general public. Second, EQ-5D+C health states were valued by means of the person trade-off (PTO) method, whereas EQ-5D health states were valued by means of the time trade-off (TTO) method [27]. PTO differs from TTO in that subjects are required to trade-off person years lived healthy against person years lived with some defined disability, thus making choices in the context of a decision involving other people rather than themselves. Whether the PTO technique is able to reflect actual preferences is still under debate $[55,56]$. Finally, besides the EQ-5D+C health state description, subjects were given specific information with respect to the disease, which differs from the EQ-5D valuation procedure [27]. Therefore, in our opinion, no valid comparison of EQ-5D+C disability weights with EQ-5D utility scores can be made. In order to develop a new scor- ing algorithm of which utility scores for the EQ-5D+C can be deduced, a valuation procedure similar to the one used for the EQ-5D should be applied. Presenting EQ-5D+C health states to members of the general population should reduce the framing effect described earlier, as the cognitive dimension will then be 'just' one of the six dimensions in the health states. Furthermore, although in the descriptive part of the EQ-5D a proxy effect may still be present, by using a utility score based on valuations of the general population, possible proxy effects are expected to decrease.

\section{Conclusion}

In this explorative study, the construct validity and responsiveness of the $\mathrm{EQ}-5 \mathrm{D}$ and the $\mathrm{EQ}-5 \mathrm{D}+\mathrm{C}$ were assessed and compared in patients aged 55 and older with

Table 6: Means of the change scores of the EQ-5D, the EQ-5D+C and the MMSE

\begin{tabular}{lcc}
\hline Change scores $\mathbf{N}=196$ & Baseline \& $\mathbf{6}$ months Mean (SD) & Baseline \& I 2 months Mean (SD) \\
\hline EQ-5D: & & $-0.07(0.31)$ \\
Utility score & $0.02(0.29)$ & $0.02(0.53)$ \\
Mobility & $-0.01(0.44)$ & $0.38(0.71)$ \\
Self-Care & $0.12(0.58)$ & $0.25(0.69)$ \\
Usual activities & $0.09(0.70)$ & $-0.06(0.67)$ \\
Pain/Discomfort & $-0.08(0.58)$ & $-0.13(0.74)$ \\
Anxiety/Depression & $-0.14(0.66)$ & $-2.46(21.40)$ \\
VAS & & \\
EQ-5D+C: & $-1.06(18.00)$ & $0.17(0.66)$ \\
Cognition & & $-4.05(21.33)$ \\
VAS & & \\
MMS+C & $0.06(0.63)$ & $-2.61(5.17)$ \\
Mean (SD) & $-1.02(18.36)$ & \\
\hline
\end{tabular}


cognitive impairments. We conclude that the EQ-5D performs well for evaluating HRQoL in our population with cognitive impairments using proxy ratings. Therefore, based on the results of this study and given its (serious) limitations, it does not seem necessary to adjust the current classification system by adding a cognitive dimension. However, in the absence of a gold standard for measuring HRQoL, a general population study to obtain valuations for the $\mathrm{EQ}-5 \mathrm{D}+\mathrm{C}$ health states could provide a better insight into whether cognition has a separate and significant effect on utility values, and would enable us to compare the utility values deduced from both versions in a correct manner.

\section{Competing interests}

The author(s) declare that they have no competing interests.

\section{Authors' contributions}

FV was the principal investigator of the larger trial and is guarantor. FV, AK, CD, and JS designed this trial. CW and DW carried out the outcome measures. AK and CW were responsible for statistical analysis and interpretation of the study, and all authors contributed to interpretation. CW drafted the manuscript, and all authors critically revised it for scientific content and approved the final version.

\section{Acknowledgements}

The MEDICIE study is funded by the Dutch Research Institute for CareMedical Sciences (ZorgOnderzoek Nederland-Medische wetenschappen, ZON-Mw), grant no. 945-02-055.

\section{References}

I. Holland R, Smith RD, Harvey I, Swift L, Lenaghan E: Assessing quality of life in the elderly: a direct comparison of the EQ-5D and AQoL. Health Econ 2004, 13:793-805.

2. van Velden ME, Severens JL, Novak A: Economic evaluations of healthcare programmes and decision making: the influence of economic evaluations on different healthcare decisionmaking levels. Pharmacoeconomics 2005, 23:1075- 1082.

3. Brooks R: EuroQol: the current state of play. Health Policy 1996, 37:53-72.

4. EuroQol-a new facility for the measurement of healthrelated quality of life. The EuroQol Group. Health Policy 1990, 16:199-208.

5. Brazier J, Roberts J, Deverill M: The estimation of a preferencebased measure of health from the SF-36. Journal of Health Economics 2002, 21:27I-292.

6. Feeny D, Furlong W, Boyle M, Torrance GW: Multi-attribute health status classification systems. Health Utilities Index. Pharmacoeconomics 1995, 7:490-502.

7. Brazier J, Roberts J, Tsuchiya A, Busschbach J: A comparison of the EQ-5D and SF-6D across seven patient groups. Health Economics 2004, 1 3:873-884.

8. Brazier J, Deverill M, Green C, Harper R, Booth A: A review of the use of health status measures in economic evaluation. Health Technology Assessment 1999, 3: I-I64.

9. Konig HH, Ulshofer A, Gregor M, von Tirpitz C, Reinshagen M, Adler G, Leidl R: Validation of the EuroQol questionnaire in patients with inflammatory bowel disease. European Journal of Gastroenterology \& Hepatology 2002, 14:|205-1215.
10. Nowels D, McGloin J, Westfall JM, Holcomb S: Validation of the EQ-5D quality of life instrument in patients after myocardial infarction. Quality of Life Research 2005, 1 4:95- 105.

II. Ankri J, Beaufils B, Novella JL, Morrone I, Guillemin F, Jolly D, Ploton $L$, Blanchard F: Use of the EQ-5D among patients suffering from dementia. Journal of Clinical Epidemiology 2003, 56: I 055- 1063.

12. Selai C: Using the EuroQol (EQ-5D) in Dementia. In Proceedings of the EuroQol Plenary Meeting, 2-3 October 1997 Volume 157. Edited by: Rabin R, Busschbach J, Charro F, Essink-Bot M, Bonsel G. Rotterdam: Erasmus University; 1998:168.

13. Bryan S, Hardyman W, Bentham P, Buckley A, Laight A: Proxy completion of EQ-5D in patients with dementia. Quality of Life Research 2005, 14:107-II8.

14. Hoeymans N, van Lindert H, Westert GP: The health status of the Dutch population as assessed by the EQ-6D. Quality of Life Research 2005, 14:655-663.

15. Krabbe PF, Stouthard ME, Essink-Bot ML, Bonsel GJ: The effect of adding a cognitive dimension to the EuroQol multiattribute health-status classification system. Journal of Clinical Epidemiology 1999, 52:293-301.

16. Selai C: Assessing quality of life in dementia. Medical Care 200I, 39:753-755.

17. Jonsson L, Andreasen N, Kilander L, Soininen H, Waldemar G, Nygaard H, Winblad B, Jonhagen ME, Hallikainen M, Wimo A: Patientand proxy-reported utility in Alzheimer disease using the EuroQoL. Alzheimer Disease and Associated Disorders 2006, 20:49-55.

18. APA: Practice guideline for the treatment of patients with Alzheimer's disease and other dementias of late life. American Psychiatric Association. American Journal of Psychiatry 1997, I54:I-39.

19. Murray CJL, Lopez LD: The Global Burden of Disease: A Comprehensive Assessment of Mortality and Disability from Diseases, Injuries, and Risk Factors in 1990 and Projected to 2020 Geneva: Harvard School of Public Health/World Health Organization; 1996.

20. Wolfs C, Severens J, Dirksen C, Kessels A, Jaspers N, Verhey F: A Randomized Clinical Trial on the Effects of a Diagnostic Observation Centre for PsychoGeriatric Patients (DOCPG). International Psychogeriatrics 2005, 17:370-371.

21. McKhann G, Drachman D, Folstein M, Katzman R, Price D, Stadlan EM: Clinical diagnosis of Alzheimer's disease: report of the NINCDS-ADRDA Work Group under the auspices of Department of Health and Human Services Task Force on Alzheimer's Disease. Neurology 1984, 34:939-944.

22. Folstein MF, Folstein SE, McHugh PR: "Mini-mental state". A practical method for grading the cognitive state of patients for the clinician. Journal of Psychiatric Research 1975, I 2: 189-198.

23. Wagner MT, Nayak M, Fink C: Bedside screening of neurocognitive function. In Psychological Assessment in Medical Rehabilitation Edited by: Cushman LA, Scherer MJ. Washington, DC: American Psychological Association; 1995:145-198.

24. Kok R, Verhey F: Dutch translation of the Mini Mental State Examination (Folstein et al., 1975). 2002.

25. Lamers LM, Stalmeier PF, McDonnell J, Krabbe PF, van Busschbach J]: Kwaliteit van leven meten in economische evaluaties: het Nederlands EQ-5D-tarief. Nederlands Tijdschrift voor Geneeskunde 2005, 149:1574-1578.

26. Lamers L, McDonnell J, Stalmeier P, Krabbe PFM, van JB: The Dutch tariff: results and arguments for an effective design for national EQ-5D valuation studies. Health Economics in press.

27. Dolan P: Modeling valuations for EuroQol health states. Medical Care 1997, 35:1095-I 108.

28. Kind P: Guidelines for value sets in economic and on-economic studies using EQ-5D. In The measurement and valuation of health status using EQ-5D: A European perspective Edited by: Brooks R, Rabin R, Charro Fd. The Netherlands: Kluwer Academic Publishers; 2003.

29. Solberg TK, Olsen JA, Ingebrigtsen T, Hofoss D, Nygaard OP: Health-related quality of life assessment by the EuroQol-5D can provide cost-utility data in the field of low-back surgery. European Spine Journal 2005, 14:1000-1007.

30. СBO: Richtlijn diagnostiek en medicamenteuze behandelingvan dementie (Guideline diagnostics and medicinal treatment of dementia). Utrecht: CBOIMWR 2005:I-75.

31. Norman GR, Stratford P, Regehr G: Methodological problems in the retrospective computation of responsiveness to change: 
the lesson of Cronbach. Journal of Clinical Epidemiology 1997, 50:869-879.

32. Terwee CB, Dekker FW, Wiersinga WM, Prummel MF, Bossuyt PM: On assessing responsiveness of health-related quality of life instruments: guidelines for instrument evaluation. Quality of Life Research 2003, 1 2:349-362.

33. Rubin DB, Schenker N: Multiple imputation in health-care databases: an overview and some applications. Statistics in Medicine 1991, 10:585-598

34. Cohen RA, Moser DJ, Clark MM, Aloia MS, Cargill BR, Stefanik S, Albrecht A, Tilkemeier $P$, Forman DE: Neurocognitive functioning and improvement in quality of life following participation in cardiac rehabilitation. American Journal of Cardiology 1999, 83:1374-1378

35. Schrag A, Selai C, Davis J, Lees AJ, Jahanshahi M, Quinn N: Healthrelated quality of life in patients with progressive supranuclear palsy. Movement Disorders 2003, 18:|464-| 469.

36. Degl'Innocenti A, Elmfeldt $D$, Hansson L, Breteler M, James $O$, Lithell H, Olofsson B, Skoog I, Trenkwalder P, Zanchetti A, Wiklund I: Cognitive function and health-related quality of life in elderly patients with hypertension-baseline data from the study on cognition and prognosis in the elderly (SCOPE). Blood Press 2002, II:157-165

37. Banerjee S, Smith SC, Lamping DL, Harwood RH, Foley B, Smith P, Murray J, Prince M, Levin E, Mann A, Knapp M: Quality of life in dementia: more than just cognition. An analysis of associations with quality of life in dementia. Journal of Neurology, Neurosurgery and Psychiatry 2006, 77:146-148.

38. Landis JR, Koch GG: The measurement of observer agreement for categorical data. Biometrics 1977, 33:159-174.

39. Marra CA, Woolcott JC, Kopec JA, Shojania K, Offer R, Brazier JE, Esdaile JM, Anis AH: A comparison of generic, indirect utility measures (the HUI2, HUI3, SF-6D, and the EQ-5D) and disease-specific instruments (the RAQoL and the HAQ) in rheumatoid arthritis. Social Science \& Medicine 2005, 60:157|-1582

40. Wu AW, Jacobson KL, Frick KD, Clark R, Revicki DA, Freedberg KA, Scott-Lennox J, Feinberg J: Validity and responsiveness of the euroqol as a measure of health-related quality of life in people enrolled in an AIDS clinical trial. Quality of Life Research 2002, I I:273-282.

41. Haywood KL, Garratt AM, Dziedzic K, Dawes PT: Generic measures of health-related quality of life in ankylosing spondylitis: reliability, validity and responsiveness. Rheumatology (Oxford) 2002, 41:1380-1387.

42. Pickard AS, Johnson JA, Feeny DH: Responsiveness of generic health-related quality of life measures in stroke. Quality of Life Research 2005, | 4:207-219.

43. Lindeboom R, Sprangers MA, Zwinderman AH: Responsiveness: a reinvention of the wheel? Health \& Quality of Life Outcomes 2005 3:8.

44. Streiner DL: Clinimetrics vs. psychometrics: an unnecessary distinction [comment]. Journal of Clinical Epidemiology 2003 56: I |42-I | 45. discussion I| 46-II 49 .

45. Tversky A, Kahneman $D$ : The framing of decisions and the psychology of choice. Science 198I, 2 I I:453-458.

46. Parkin D, Rice N, Jacoby A, Doughty J: Use of a visual analogue scale in a daily patient diary: modelling cross-sectional timeseries data on health-related quality of life. Social Science \& Medicine 2004, 59:35I-360.

47. Smith SC, Lamping DL, Banerjee S, Harwood R, Foley B, Smith $P$, Cook JC, Murray J, Prince M, Levin E, Mann A, Knapp M: Measurement of health-related quality of life for people withdementia: development of a new instrument (DEMQOL) and an evaluationof current methodology. Health Technology Assessment 2005, 9: I-93. iii-iv

48. Albert SM, Del Castillo-Castaneda C, Sano M, Jacobs DM, Marder K Bell K, Bylsma F, Lafleche G, Brandt J, Albert M, Stern Y: Quality of life in patients with Alzheimer's disease as reported by patient proxies. Journal of the American Geriatrics Society 1996, 44: $1342-1347$

49. Magaziner J: Use of proxies to measure health and functional outcomes in effectiveness research in persons with Alzheimer disease and related disorders. Alzheimer Disease and Associated Disorders 1997, I I (Suppl 6): I68-174.
50. Logsdon RG, Gibbons LE, McCurry SM, Teri L: Assessing quality of life in older adults with cognitive impairment. Psychosomatic Medicine 2002, 64:510-519.

51. Mathers CD, Vos ET, Stevenson CE: The burden of disease and injury in Australia. Canberra: Australian Institute of Health and Welfare; 1999.

52. Mathers CD, Vos ET, Stevenson CE, Begg SJ: The burden of disease and injury in Australia. Bull World Health Organ 200I, 79: 1076-1084.

53. Stouthard M, Essink-Bot M, Bonsel G, Barendregt J, Kramer $P$, van de Water H, Gunning-Schepers L, van der Maas P: Disability Weights for Diseases in the Netherlands. Rotterdam: Erasmus University; 1997.

54. on behalf of the Dutch Disability Weights (DDW) Group, Stouthard M, Essink-Bot M, G] B: Disability weights for diseases. A modified protocol and results for a Western European region. European Journal of Public Health 2000, 10:24-30.

55. Pinto-Prades J: Is the person trade-off a valid method for allocating health care resources? Health Economics 1997, 6:7I-8I.

56. Green C: On the societal value of health care: what do we know about the person trade-off technique? Health Economics 200I, 10:233-243.

Publish with BioMed Central and every scientist can read your work free of charge

"BioMed Central will be the most significant development for disseminating the results of biomedical research in our lifetime. "

Sir Paul Nurse, Cancer Research UK

Your research papers will be:

- available free of charge to the entire biomedical community

- peer reviewed and published immediately upon acceptance

- cited in PubMed and archived on PubMed Central

- yours - you keep the copyright
BiolMedcentral 